\title{
Macroscopic Modelling of Environmental Influence on Growth and Form of Sponges and Corals Using the Accretive Growth Model
}

\author{
Jaap A. Kaandorp \\ Section Computational Science, Faculty of Science, University of Amsterdam, Science Park 904, 1098 XH Amsterdam, The Netherlands \\ Correspondence should be addressed to Jaap A. Kaandorp; j.a.kaandorp@uva.nl \\ Received 10 December 2012; Accepted 17 January 2013 \\ Academic Editors: M. Glavinovic, S.-C. Ngan, and A. A. Polezhaev \\ Copyright (C) 2013 Jaap A. Kaandorp. This is an open access article distributed under the Creative Commons Attribution License, \\ which permits unrestricted use, distribution, and reproduction in any medium, provided the original work is properly cited. \\ We discuss a macroscopical growth model which can be used to simulate growth forms of complex-shaped branching organisms \\ with radiate accretive growth. This type of growth processes can be found in many different marine sessile organisms. We use \\ scleractinian corals and a branching sponge as an example. With the radiate accretive growth model a wide range of morphologies \\ and the influence of the physical environment (light and nutrient distribution by advection-diffusion) can be modelled. We show an \\ (preliminary) example of how the accretive growth model can be coupled with a model of gene regulation and body plan formation \\ in a branching sponge.
}

\section{Introduction}

Many marine sessile organisms from very different taxonomical groups show a strong morphological plasticity, which is in many cases related to the impact of the physical environment. Two dominant parameters influencing morphological plasticity are water movement and the availability of light in photosynthetic organisms. Environmental parameters, closely linked to water movement, are the supply of suspended material in filter-feeding organisms and sedimentation. Sedimentation may also strongly influence the availability of light. Examples of studies in which the morphological plasticity and the relation to physical environment have been investigated are growth forms of the scleractinian Montastrea annularis and local light intensities [1,2]; growth forms of the hydrozoan Millepora and the exposure to water movement [3, 4]; variations in morphology due to differences in exposure to water movement in the scleractinians Pocillopora $[5,6]$, Madracis [7, 8], and Agaricia agaricites [9]; colony forms of the bryozoan Electra pilosa and the influence of nutrient supply [10]; shape of coralline algae and the effect of exposure to water movement [11]; growth forms of the sponge Haliclona oculata $[12,13]$ and exposure to water movement. A detailed review on the morphological plasticity in corals and the influence of the environment can be found in a recent paper by Todd [14].

There are a large number of studies [14] where scleractinian coral colonies have been transplanted from one environment to a different one to identify the impact of the physical environment on the growth form of the colony. In [4] hydrozoan colonies (Millepora) and in [13] sponges (Haliclona oculata) were transplanted from sheltered to exposed environment and vice versa. There are a number of problematic issues in these experiments. The first issue is that many transplantation experiments were done with organisms or colonies which were not necessarily of the same genotype, and in this nonclonal approach it cannot be excluded that morphological changes are caused by the genotype and not by the influence of the environment. By using clone mates (e.g., fragments of the same colony or individual) it is basically possible to determine the morphological response to the environment. The second issue is that the interaction between the physical environment (flux of nutrients over boundary layers, local flow velocities, and local light intensities) and local growth velocities is very difficult (if not impossible) to assess in detail in experiments. An alternative option is to use simulation models where these quantities can be estimated in great detail. By using simulation models it is also possible to 
obtain a deeper insight into the morphogenetic process itself and to find mathematical rules capturing the biomechanics of the growth process of a coral colony or a sponge and the impact of the physical environment on morphogenesis. The third issue is that the morphological changes at the organismal level due to transplantation experiments are, especially in three-dimensional complex-shaped branching forms, are difficult to be interpreted and to be quantified. A solution here is to use detailed morphometric methods to detect local changes in the growth, form $[8,15]$. An important complication in the quantitative morphological analysis of growth forms of scleractinian corals, sponges and many other marine sessile organisms is that the growth forms are usually indeterminate and complex. Most methods for the analysis of growth and form use landmark-based geometric morphometrics $[16,17]$. These methods are more suitable for unitary organisms and less applicable for the analysis of indeterminate growth forms of modular organisms [1823]. In a number of cases, the organism is built from welldefined modules (e.g., the corallites and polyps in scleractinian corals). In other cases, the module itself has no well-defined shape but an irregular and indeterminate form (e.g., an osculum and its corresponding aquiferous system in sponges).

1.1. Scleractinian Corals. Water flow has a strong influence on the growth process of several scleractinian corals. Veron and Pichon [24] present several series of growth forms of scleractinians (e.g., Pocillopora damicornis and Seriatopora hystrix), which are arranged along a gradient of increasing water movement. Both species show a gradual transformation from a compact shape with a relatively low branch spacing, under exposed conditions, to a thin-branching shape with a relatively larger branch-spacing under sheltered conditions. In the Caribbean coral Madracis mirabilis a similar range, compact growth forms with a low branch spacing gradually changing into more open thin-branching forms with a larger branch spacing, is found. Two examples of growth forms of the two extremes, the thin-branching low-flow morph collected from a depth of $20 \mathrm{~m}$ and the compact hemispherical high-flow morph collected from a depth of $6 \mathrm{~m}$, are shown in Figures 1(a) and 1(b). At the site where the samples were collected water movement at $6 \mathrm{~m}$ is on average 2.3 times higher compared to the site at $20 \mathrm{~m}$ [25]. Earlier experiments with branching corals in flume studies [26] showed that densely packed branching colonies, comparable to Madracis mirabilis colonies, act as a solid body. Water flow (even for relatively high-flow velocities such as $20 \mathrm{~cm} \mathrm{~s}^{-1}$ ) starts to circumvent the colony, and a stagnant region develops inside the colony. The authors suggest that the water velocity inside colonies reaches an upper limit, a relatively low (compared with the water velocity externally of the colony) saturation velocity. In [5] data is provided about flow velocities around Pocillopora damicornis colonies. For high-flow morphs an external flow velocity of about $8 \mathrm{~cm} \mathrm{~s}^{-1}$ and inside colony flows of around $1 \mathrm{~cm} \mathrm{~s}^{-1}$ were found. For the low-flow morphs an external flow velocity of about $3 \mathrm{~cm} \mathrm{~s}^{-1}$ and inside colony flow of $0.8 \mathrm{~cm} \mathrm{~s}^{-1}$ were reported.
Hydrodynamics affects the distribution of food particles $[7,27]$ and dissolved material $[5,6,28-42]$ in the immediate environment of the coral. For zooxanthellate corals, calcification depends on a phototrophic component related to local availability of light and local gradients of dissolved inorganic carbon $[5,36,37]$ and a heterotrophic component related to the uptake of nutrients from the environment. The relative contribution of the phototrophic and heterotrophic components can be estimated from skeletal $\delta^{13} \mathrm{C}$ and $\delta^{18} \mathrm{O}$ isotopes. [43-45]. In [45] it was demonstrated that the calcification of $M$. mirabilis is mainly supported by photosynthesis based on the analysis of the $\delta^{13} \mathrm{C}$ and $\delta^{18} \mathrm{O}$ isotopes. If photosynthesis is the main source of energy, then local gradients of inorganic carbon will play a crucial role in the morphogenesis of $M$. mirabilis as they represent a limiting resource to skeleton formation. In recent field experiments by Mass et al. [46-48] and simulation experiments [6] it was found that Pocillopora verrucosa develops asymmetrical colonies due to the influence of an asymmetric directed flow. The increase in fluid motion around organism is believed to increase nutrient transport and uptake and ultimately enhances the organism's growth rate [49].

Morphological plasticity is directly related to various biologically relevant parameters as, for example, the diameter of the branches, branching rate, branching angles, and branch spacing in scleractinian corals. In, for example, studies on particle capture in the branching scleractinian coral $M$. Mirabilis and the influence of hydrodynamics [7], it was demonstrated that branch diameters and branch spacing are crucial morphological properties. The diameter of the branches and spacing between branches are variable and may be controlled by a combination of hydrodynamics and genetics. In [7] it is argued that through modifications of its branch structure and branch spacing, M. mirabilis can function efficiently as a passive suspension feeder over a wide range of exposure levels to water movement. In a study by Bruno and Edmunds [50] on M. mirabilis it is demonstrated that by increasing the branch spacing the thickness of the diffusive boundary layer is effectively decreased and mass transport and high respiration rates even under low flow conditions can be maintained.

In [2] transplantation experiments with nonclonal colonies of Montastrea annularis and morphological simulation models were used to investigate the influence of local light intensities on the growth process and the overall colony morphology. Montastrea annularis shows a hemispherical colony form under circumstances with a maximum light intensity, when the colony grows close to the water surface. The colony gradually transforms from hemispherical through column-shaped and tapered forms to a substrate-covering plate when the light intensity decreases. In [51] a combination of transplantation experiments (using clonal transplants) and simulation models was used to demonstrate that the morphological plasticity in Porites sillimaniani is related to the availability of light. In the transplantation experiments it was shown that colonies under high light conditions developed branches while under low light conditions remained flat. 
1.2. Sponges. In growth forms of the sponge Haliclona oculata plate-like, more compact shapes emerge at exposed sites (Figure $1(\mathrm{~d})$ ), and this shape gradually transforms into a thinbranching form (Figure 1(c)), when the exposure to water movement decreases $[12,52-54]$. A major component in the growth process of a sponge is the pump system with which suspended material is collected from the environment and transported through the sponge tissue $[55,56]$, the aquiferous system. The aquiferous system consists of inhalant pores where water together with suspended material enters the sponge. The filtered water leaves the sponge again through the oscula, the exhalant apertures of the sponge. The aquiferous system of Haliclona oculata is poorly developed in comparison to a related species such as Haliclona simulans [57] where the oscula are very clearly visible as holes in the growth form. In Haliclona oculata, only close to the oscula macroscopic evidence of canals is found. In Haliclona simulans the aquiferous system is far more evolved and visible as an extensive system of canals. Probably the aquiferous system of Haliclona oculata is strongly supported by external water movements as well (cf. [58]). Under conditions with strong water movements plate-like growth forms are possible as shown in Figure 1(b), whereas in sheltered conditions a decrease of food supply will occur in the tissue, unless it is in short-distance contact with the environment; in this case only thin-branching forms (e.g., Figure 1(a)) will occur. In the related species $H$. simulans with a more evolved aquiferous system, relatively wide branches and more globular forms are found. The development of the aquiferous system is a species-specific pattern in sponges which is another major component determining the resulting growth form.

1.3. Accretive Growth. In many marine sessile organisms a skeleton is formed by a surface normal deposition process. In this growth process skeleton material is deposited on top of previous layers, which remain unchanged, during the growth process as shown in Figure 2. In many cases the skeleton formed in this growth process is characterized by a radiate accretive architecture (see, e.g., the sponge Haliclona oculata in Figure 2(a)); a similar architecture is found in many scleractinian corals [2]; for example, in Montastrea annularis in Figure 2(b) this structure is very well visible. A diagram of the layered structure formed by the accretive growth process is shown in Figure 2(c). The growth process in these organisms may be driven almost exclusively by the local availability of light required for the photosynthesis. In predominant autotrophic scleractinian corals (e.g., Montastrea annularis) there is a direct relation between local deposition velocities and local light intensities on the surface of the colony. Alternatively the growth process may be entirely driven by the absorption of nutrients from the surrounding environment as, for example, in the heterotrophic sponge Haliclona oculata. In many scleractinian corals and phototrophic sponges a mixture of both energy sources will be used.

In this paper we discuss a computational model which can be used to simulate the growth process in an organism with a radiate accretive growth process. This method can be used to simulate the accretive growth process in corals and sponges.
Potentially many other organisms from different taxonomical groups [56], for example, stromatolites $[59,60]$ and coralline algae [11] with a similar radiate accretive structure as shown in Figure 2(c), can be captured with this model. The model can be used to investigate the influence of light on the local growth process and the influence of advection diffusion on the local absorption of nutrients (as, e.g., inorganic carbon or silicate) at the surface of the coral or a sponge. The results shown in this paper are based on a number of earlier publications $[6,8,56,61-67]$. The model of the physical environment can be used to study the hydrodynamics and local distribution of nutrients and light in coral morphologies. The morphological simulation model, the accretive growth model in combination with an advection-diffusion model, can be used to study the hypothesis that external gradients of inorganic carbon in the boundary layers of the colony or silicate in a sponge and local light intensities are shaping the organism with radiate accretive growth. Finally we show a (highly preliminary) model of radiate accretive growth model in a sponge which is combined with a spatiotemporal model of gene regulation in a branching sponge [61].

\section{Methods}

2.1. Biological Background of Accretive Growth in Scleractinian Corals. In X-ray studies it was demonstrated that a corallite in scleractinian coral tends to be set normal with respect to the previous growth layers $[68,69]$. This normal deposition process can especially very well be visualized in Montastrea annularis. In Figure 2(a) a volume rendered [70] slice of this coral is shown. In this picture the slice is slightly rotated. Part of the original surface of the colony is shown, and a length section is made through the colony. At the surface the position of the corallites is visible as dark coloured pores, while the annual growth of the colony is visible as density bands in the section of the colony. From the density bands it is, at least in theory, possible to reconstruct the surface of the colony in earlier growth stages. This section shows that the corallites are set perpendicular with respect to the previous growth layer. In the study by [69] examples are shown of X-ray pictures of a branching coral (Porites porites) in which annual growth is visible in $\mathrm{X}$-ray pictures of sections through the colony and where it can also be observed that the corallites are set perpendicular with respect to previous growth layers. The corallite moves outward with the (living) peripheral tissue and leaves a growth trajectory which can be reconstructed by connecting the positions of the centre of a corallite in the successive growth layers.

\subsection{Biological Background of Accretive Growth in Sponges. In} sponges, only species, as, for example, Haliclona oculata and Lubomirskia baikalensis with a certain kind of skeleton architecture can develop erect tree-like growth forms [56, 71, 72], as shown in Figures 1(c) and 1(d). The skeleton architecture, emerges in an accretive growth process where the individual skeleton elements (the spicules) are arranged in a radiate accretive architecture [73]. In this growth process growth only occurs at the tip of the sponge, where new layers are deposited 


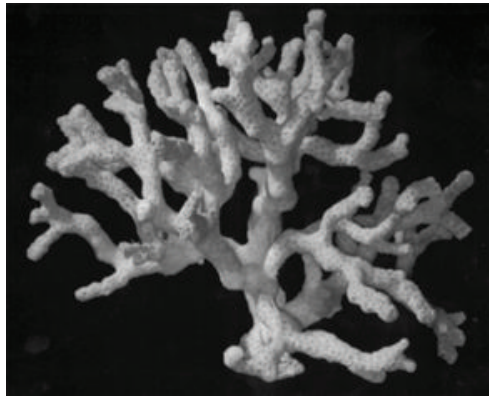

(a)

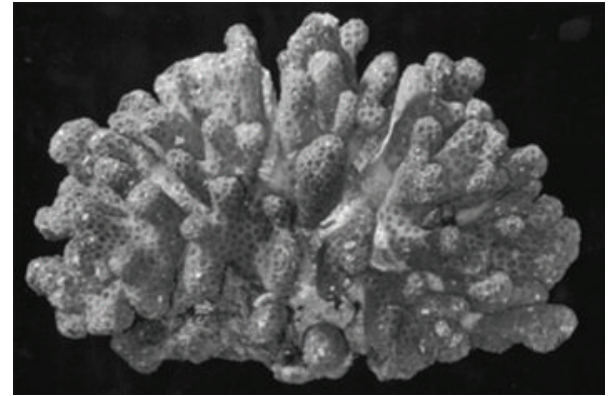

(b)

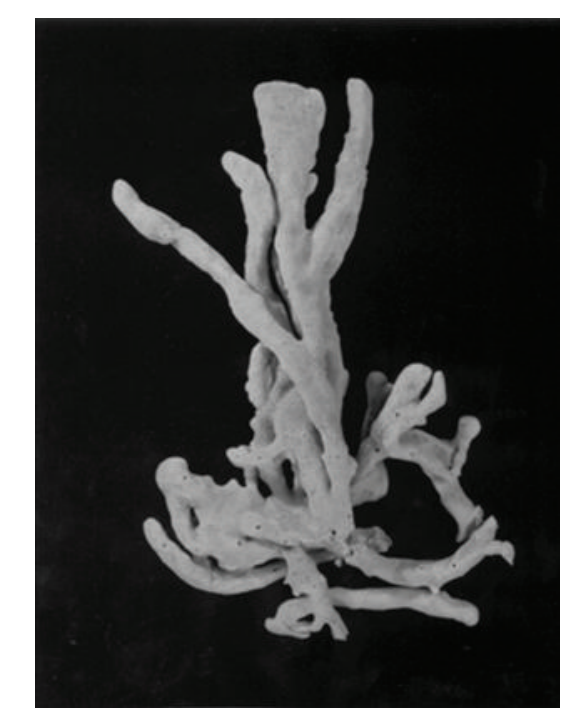

(d)

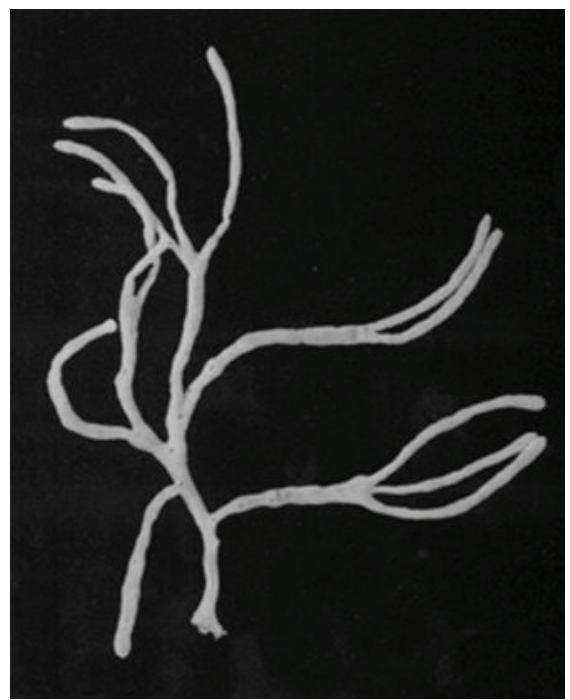

(c)

FiguRE 1: ((a) and (b)) Growth forms of the scleractinian coral Madracis mirabilis ((a) a low-flow morphology and (b) a growth form from a more exposed location). ((c) and (d)) The sponge Haliclona oculata ((c) a typical thin-branching form and (d) a high-flow morphology).

on top of the previous layers, while the previous growth stages remain unchanged. In Figure 2(b) a longitudinal section through the branching sponge Haliclona oculata is shown. In the sponge case the skeleton consists of silicified material (the spicules), where spicules are connected in bundles and are set perpendicular with respect to the previous surface and where spicules cover the surface of a growth layer and are organized in polygonal way, where every edge of a polygon consists of a spicule. In some Haliclona species ( $H$. simulans) the spicules in the growth layers are arranged in triangles and in H. oculata the spicules are arranged in a polygonal pattern, which can be subdivided again in a triangular pattern (for detailed drawings of the spicule architecture in Haliclona species see [56]).

2.3. Simulating the Accretive Growth Process. In the simulation model it is assumed that the living tissue deposits new layers of material on top of the previous layers, which remain unchanged. The growth layers are represented by layers of triangles, which are again organized in a polygonal pattern as shown in Figure 2(c). This is demonstrated in Figure 3 where two initial simulated growth stages are shown. In Figure 3(a) the initial object used in the simulations is shown: a sphere tessellated with triangles, where the triangles are organized in a pattern of penta- and hexagons. In Figure 3(b) the next growth stage is shown in which a layer is constructed on top (in the vertical direction) of the previous growth stage. In Figure 3(b) the object has slightly grown in the vertical direction. In the growth model we assume that some nutrient (e.g., dissolved inorganic carbon in scleractinian corals or silicate in sponges) is the main limiting factor in the formation of the skeleton.

The basic idea of the simulation model is shown in Figure 4: nutrients are released from the top plane (the source 


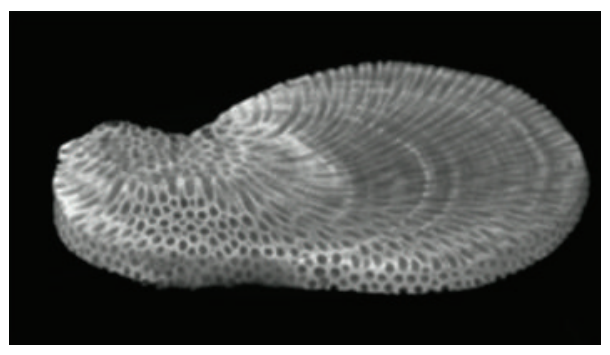

(a)

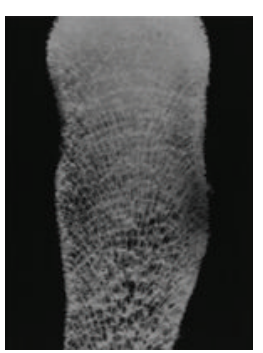

(b)

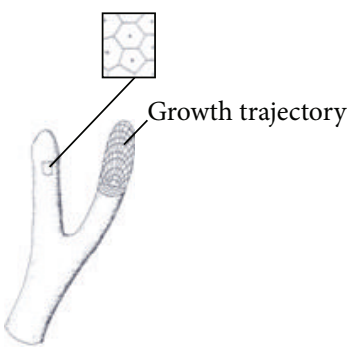

(c)

FIgURE 2: (a) Volume rendered slice of the scleractinian coral Montastrea annularis. The slice is slightly rotated showing part of the surface and a length section through the colony. The position of the corallites is visible as dark colored pores at the surface, while the annual growth of the colony is visible as density bands in the section of the colony. (b) Longitudinal section through a branch of the sponge Haliclona oculata as seen through a stereomicroscope showing the skeleton architecture (all soft tissues have been removed). (c) Diagram of the accretive growth process showing the deposition of new layers of material on top of the previous one.

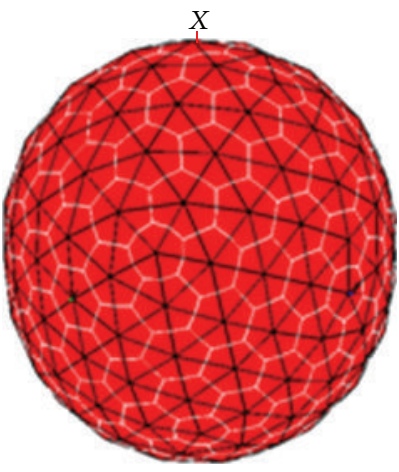

(a)

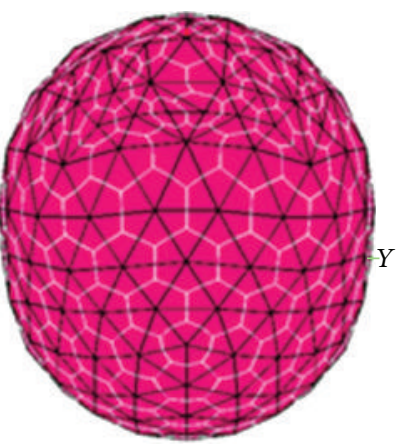

(b)

Figure 3: Two successive objects generated with the radiate accretive growth model. The object shown in (a) is the initial object used in the simulations. The polygons shown in both objects represent the corallites in scleractinian corals or the network of spicules in the sponges in the simulations.

plane) in the simulation box and a simple parallel light source is assumed, where the light direction corresponds to the vertical. The flow about the object can be simulated in a computational model where the flow field $\vec{u}=\left(u_{u}, u_{v} u_{w}\right)$ is given by the incompressible Navier-Stokes equations (NVS) and the continuity equation

$$
\begin{gathered}
\rho \frac{\partial \vec{u}}{\partial t}-\nabla \cdot\left[\eta\left(\nabla \vec{u}+\nabla \vec{u}^{T}\right)\right]+\rho(\vec{u} \cdot \nabla) \vec{u}+\nabla p=F, \\
\nabla \cdot \vec{u}=0
\end{gathered}
$$

where $F$ is the external volume force, which is set to 0 , $u$ is the fluid velocity, $p$ is the pressure, $\eta$ is the dynamic viscosity, $\rho$ is the fluid density, and $\eta\left(\nabla \vec{u}+(\nabla \vec{u})^{T}\right)$ is the stress tensor that results from the fluid viscosity. Fluid enters the simulation domain with the initial velocity $\vec{u}_{\text {in }}=-n U_{0}$, where $U_{0}$ is the uniform inlet velocity profile along the normal direction of the entry point and is set to some initial flow velocity. The boundary conditions of the substratum and surface of the simulated object are, for example, set to the no-slip condition where velocity vector $\vec{u}$ is zero. After the solutions of Navier Stokes equations are found, simulated nutrient enters the simulation domain from all sides and is absorbed by the simulated object. Subsequently, the amount of absorbed nutrients is determined by solving the advectiondiffusion equation:

$$
\frac{\partial c}{\partial t}+\vec{u} \cdot \nabla c=D \nabla^{2} c,
$$

where $c$ is the concentration gradient, $\vec{u}$ is the velocity vector obtained from the solution of the NVS equations, and $D$ is the diffusion coefficient. For computing the nutrient distribution around the object due to advection-diffusion and where nutrients are being absorbed by the object we have used two approaches. In the first approach we used a cellular-automatabased particle model, the "moment propagation" method $[74,75]$ in conjunction with the lattice Boltzmann method [76-79] to model the dispersion of nutrient in the external environment by advection-diffusion. The lattice Boltzmann method is especially suitable for developing scalable simulations (using distributed computation) of advection-diffusion processes and modelling boundary layers in complex threedimensional geometries $[62,80,81]$. With the lattice Boltzmann method and the momentum propagation method it is only possible to simulate the advection-diffusion process 
for very low-flow velocities, very close to the diffusionlimited case because of numerical instabilities $[8,63]$. In the second approach [6] we recently have solved the advectiondiffusion equations for higher flow velocities (up to $5 \mathrm{~cm} / \mathrm{s}$ by using the advection-diffusion solver from COMSOL Multiphysics [82] to solve the equations). In Figure 5 we show a schematic flow chart of the simulation model using the lattice Boltzmann method. The initial sphere (Figure 3(a)) is voxelized in a cubic lattice (b) after which the fluid flow (c) and resource dispersion are computed until stability. In each vertex of the simulated object the absorbed quantities are measured (d). In the accretion step (e), a new triangular mesh is constructed on top of the previous one. This mesh is voxelized (b), initiating a new growth cycle. The coral growth software and the lattice Boltzmann were all developed in $\mathrm{C}++$; the parallelization was done using MPI. The objects have been visualized using the General Mesh Viewer (GMV). The simulations presented in this paper were carried out on the LISA computer cluster at the Academic Computing Services Amsterdam (SARA). The cluster consists of 272 nodes, connected by an $800 \mathrm{MB} / \mathrm{s}$ Infiniband network. Each node is a dual Intel Xeon $3.4 \mathrm{Ghz}$ system with $2 \mathrm{~GB}$ of RAM, running Debian Linux. Most simulations were carried out on 8 nodes. Simulating one growth form on 8 nodes can take approximately (depending on the parameter settings) 6-8 hours of computing time. A user-friendly version of the software with the accretive growth model will be made available as open access software in the near future (http://computationalscience.uva.nl/download/PORAG).

In the advection-diffusion simulations it is assumed that nutrient is absorbed at the centres of the polygons shown in Figures 2(c) and 3. The source plane of nutrient is located at the top plane of the cube enclosing the simulated object (the simulation box in Figure 4). With the advection-diffusion solver (one of the two approaches mentioned previously) the gradients around the object are computed for every growth stage. An example of a section through a simulated growth form is shown in Figure 6(b). In this example nutrient was exclusively distributed by diffusion. The section through the simulated growth form is shown in white, while the concentration of nutrient around the object is displayed using a redyellow-green-blue colour-gradient. Red indicates the highest concentration (located at the top plane of simulation box). The solid lines in the picture depict isosurfaces with equal concentrations around the object. In the simulations nutrient is all the time absorbed at the surface of the object and at the substrate plane, resulting in nutrient depleted region close to the object (blue) where the nutrient concentration is zero.

The linear extension rate of the simulated skeleton in Figure 6(a) is driven by the amount of absorbed simulated nutrient. Quantitatively local growth at surface of object can be directly related to the amount of absorbed simulated nutrient. The addition of layers on top of previous layers is visualized in Figure 6(a). In the simulations there are only local interactions between the polygons, which are closely packed on a growth layer. The size of the simulated polygon varies around a certain (species-specific) mean size $d$ of the corallite in a scleractinian coral or a spicule in a sponge. Polygons that become too large split up into new ones, while

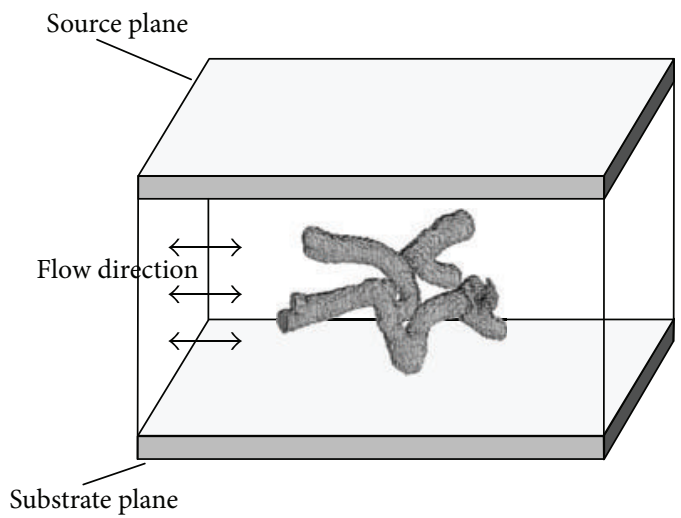

FIgURE 4: Simulation box. In the advection-diffusion simulations it is assumed that the top plane is the source plane of nutrients, while the nutrients are absorbed at the surface of the simulated growth form. In the light simulations it is assumed that the light direction corresponds to the vertical and that all light is absorbed at the surface of the object.

(a) Initial condition

(b) Voxelization

(c) Flow

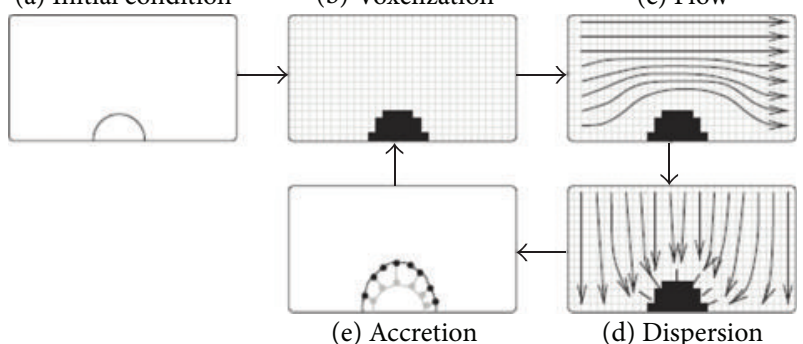

FIGURE 5: Schematic flow chart of the simulation model using the lattice Boltzmann method. The initial sphere (Figure 3(a)) is voxelized in a cubic lattice (b) after which the fluid flow (c) and resource dispersion are computed until stability. In each vertex of the simulated object the absorbed quantities are measured (d). In the accretion step (e), a new triangular mesh is constructed on top of the previous one. This mesh is voxelized (b), initiating a new growth cycle.

small ones are deleted. For further details about the splitting up and deletion of triangles, we refer to [83]. After each growth step, where a new layer of triangles is constructed on top of the previous one, the gradients computation is repeated again. Branching occurs as an emergent property of the model, where the collective behaviour of the individual absorbing vertices shapes the whole object. The model suggests a biological explanation for branching growth in scleractinian corals [64]. At convex sites, the polyps fan out, thus getting better access to the diffusing resources. At concave sites, the polyps point towards each other, thus interfering in the uptake of resources. In this way, a curvature effect comes out as a natural consequence of the competition between the polyps to take up nutrient from the surrounding environment.

The accretive growth model was used to simulate coral morphologies $[6,8,63,83]$ and sponge morphologies [12, 13, 61]. The model simulates the growth of the skeleton as 
an accretive process whereby subsequent growth layers are deposited on top of the previous one as the coral colony grows. The geometry of each layer is represented by a triangulated surface (as shown in Figures 2(c) and 3). The thickness of a new layer $l_{i+1}$, the distance between two successive vertices $V_{i}$ and $V_{i+1}$, is computed by using the growth function

$$
l=\vec{n} c_{i}^{\text {total }} s
$$

where $\vec{n}_{i}$ is the average normal vector in vertex $V_{i}, c_{i}^{\text {total }}$ is the amount of absorbed simulated nutrients and local light intensity in vertex $V_{i}$, and $s$ is the maximal thickness of the growth layer. The distance $l$ between the two layers, that is, skeleton thickness, is assumed to be linearly dependent on the amount of absorbed nutrients and local light intensity. We use

$$
c_{i}^{\text {total }}=(1-\alpha) c_{i}^{\text {nutrient }}+\alpha c_{i}^{\text {light }}, \quad 0 \leq \alpha \leq 1
$$

to compute $c_{i}^{\text {total }}$ at $V_{i}, c_{i}$ denotes the amount of absorbed nutrients or light and $\alpha$ denotes the parameter controlling relative contribution of light, intensity and nutrient concentration to the growth process. In this equation $c_{i}^{\text {light }}$ represents the local intensity in vertex $i$. The local light is computed in

$$
\begin{array}{r}
c_{i}^{\text {light }}=(1-\text { ambient }) \\
0 \leq \text { ambient } \leq 1 .
\end{array}
$$

In (5) $\theta$ is the angle between the mean normal vector in vertex $i$ and the direction to the light source; it must be between $0^{\circ}$ and $90^{\circ}$. In most cases not all light that reaches a surface comes directly from the light source. The ambient parameter is included to capture the effect of light reaching surfaces indirectly via reflections in the environment. It determines the fraction of light from the environment.

In (5) there is no shading of triangles included; to correct for shading effects by occlusion of other parts of the simulated object we have used an algorithm based on volume rendering techniques [70] in which the object is represented in a threedimensional lattice. The algorithm is described in $[53,84]$. It makes use of a voxelized representation $[65,85,86]$ of the object. We distinguish four different types of voxels: "empty," "solid," "shaded," and "illuminated" voxels. In the first step a voxelization of the surface mesh object is done, followed by a heuristic seed fill procedure [86] to completely fill the simulated object and transform the original surface into a voxelized solid object. The next step is to determine which solid voxels are illuminated and which voxels are occluded by other solid voxels. For each column of the three-dimensional lattice model (top to bottom) a ray of light is cast downward. When a voxel belonging to the object, an occupied voxel in the state "solid," is encountered, we mark it as "illuminated." Proceeding down the column we mark all subsequent voxels as illuminated, too, until we come across an unoccupied voxel. We then move to the next column.

All voxels which were not marked as illuminated are considered to be shaded. Now for each triangle of the triangulated mesh we map it onto its voxel representation and count the number of shaded and illuminated voxels. Equation
(6) is then used to correct the light intensity in at vertex $c_{i}^{\text {light }}$ in (6) for shading effects, by multiplying $c_{i}^{\text {light }}$ with the ratio of illuminated voxels and total number of voxels in a triangles surrounding vertex $i$ :

$$
\begin{aligned}
c_{i}^{\text {light }}= & c_{i}^{\text {light }} \\
& \times \frac{\# \text { voxels-illum }- \text { in }- \text { triangles }- \text { surrounding }-i}{\text { \#voxels - total-in-triangles }- \text { surrounding }-i} .
\end{aligned}
$$

The final result of these light intensity calculations is that we can compute the local light intensities in a complex-shaped branching object an shown in Figure 7. In Figure 7 the light direction corresponds to the vertical axis in the simulation box and all local light intensities at the surface are visualized and corrected for occlusion effects where the upper branches shade the lower parts of the object.

The main assumption made in the model is that the growth of the skeleton is limited by the amount of local availability of dissolved nutrient (inorganic carbon DIC or silicate in a sponge) and light in the environment. In corals higher DIC availability promotes calcification depending on light availability [87-95]; in sponges high silicate concentrations induce spicule formation [96]. Branching in the simulated object emerges from competition between the polygons for available nutrients [64].

The translocation of absorbed nutrients between the neighbouring polyps [97] in a coral is modelled by lateral diffusion across the surface of the object:

$$
\frac{\partial c(x, t)}{\partial t}=D_{\text {surf }} \nabla^{2} c(x, t)
$$

where $c$ is the concentration of nutrients at point $x$ and time $t$ and $D$ the diffusion coefficient.

The model uses several species-specific parameters such as distance $d$ between polygons (please note that $d$ is linked to $s$ in (3) and represents a characteristic length scale). By varying environmental modelling parameters such as light intensity, nutrient availability, and the degree of diffusion of the nutrients across the object surface, we can simulate various morphologies. Figures 8 and 9 show a range of morphologies which can be simulated with this model; in both Figures 8 and 9 simulated nutrient is only distributed by diffusion. In Figure 8 we investigate the impact of translocation of nutrient on the simulated morphology by varying the transport of nutrient over the surface of simulated growth form, controlled by the parameter $D_{\text {surf }}$. In the simulated forms shown in Figure 9, growth is exclusively controlled by the absorption of simulated nutrient $(\alpha=0$ in (4)). In Figure 8 we also show the influence of parameter $d$ (a species-specific parameter characterizing the typical size of a polygon). In Figure 9 we show a range of morphologies generated by a model in which both simulated nutrients and light intensities control the growth process $(\alpha=0.4$ in (4)) and the influence of changing the ambient parameter in (5) and $d$. 


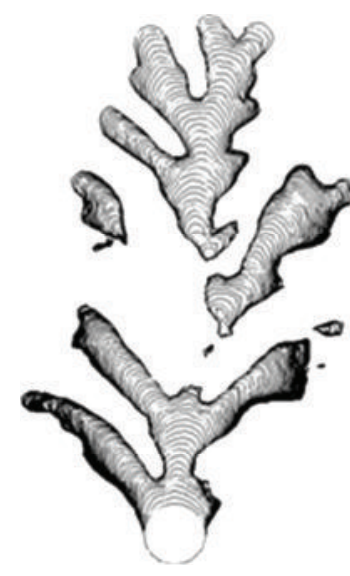

(a)

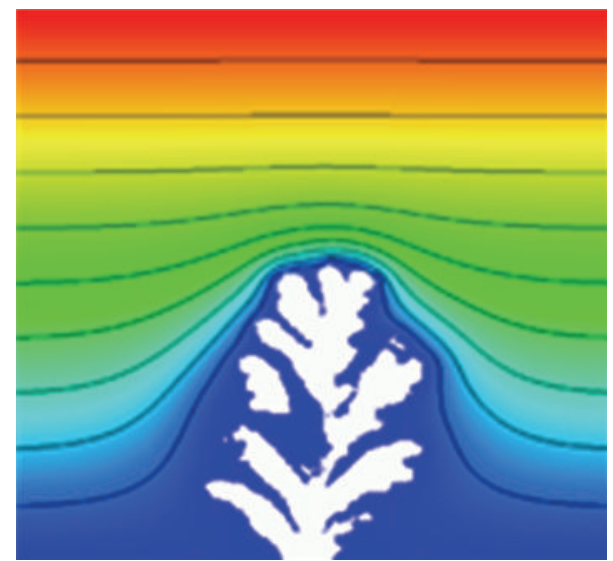

(b)

FIGURE 6: Sections through a simulated growth form. (a) Section showing the addition of layers on top of previous layers in the simulated accretive growth process. (b) The section through the simulated growth form is shown in white, while the concentration of nutrient around the object is displayed using a red-yellow-green-blue colour gradient. Red indicates the highest concentration, while blue indicates a depletion of nutrient and visualizes the region with a concentration of near zero. In this example nutrient was exclusively distributed by diffusion. The solid lines in the picture indicate isosurfaces with equal concentrations.

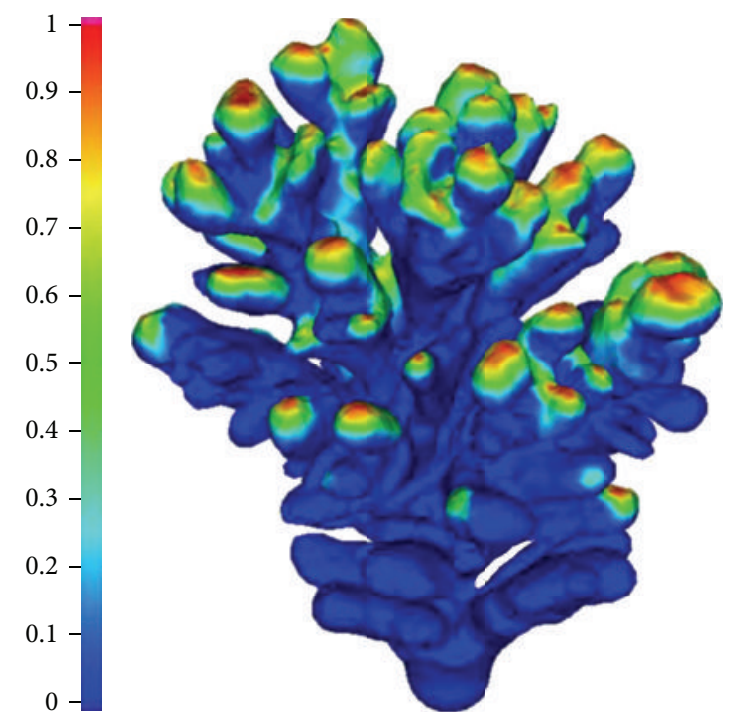

FIGURE 7: Calculated light intensities on a simulated branching object. The light direction corresponds to the vertical in the simulation box (Figure 4). The light intensities were computed with (5); the light intensities were corrected for shading by using (6). Simulated nutrient is distributed by diffusion.

\subsection{Coupling the Radiate Accretive Growth Model with a} Model of Gene Regulation in the Sponge Haliclona oculata. Recently new details [96, 98-104] about the genetic regulation of growth and form of sponges have become available, including evidence for spatial and temporal gradients of morphogens controlling the growth in a positional information system. For building a skeleton two species of silicate (silicic acid) are absorbed by the sponge from the environment. Silicate is being transferred over the diffusive boundary layer around the sponge, and local silicate is depleted. When there

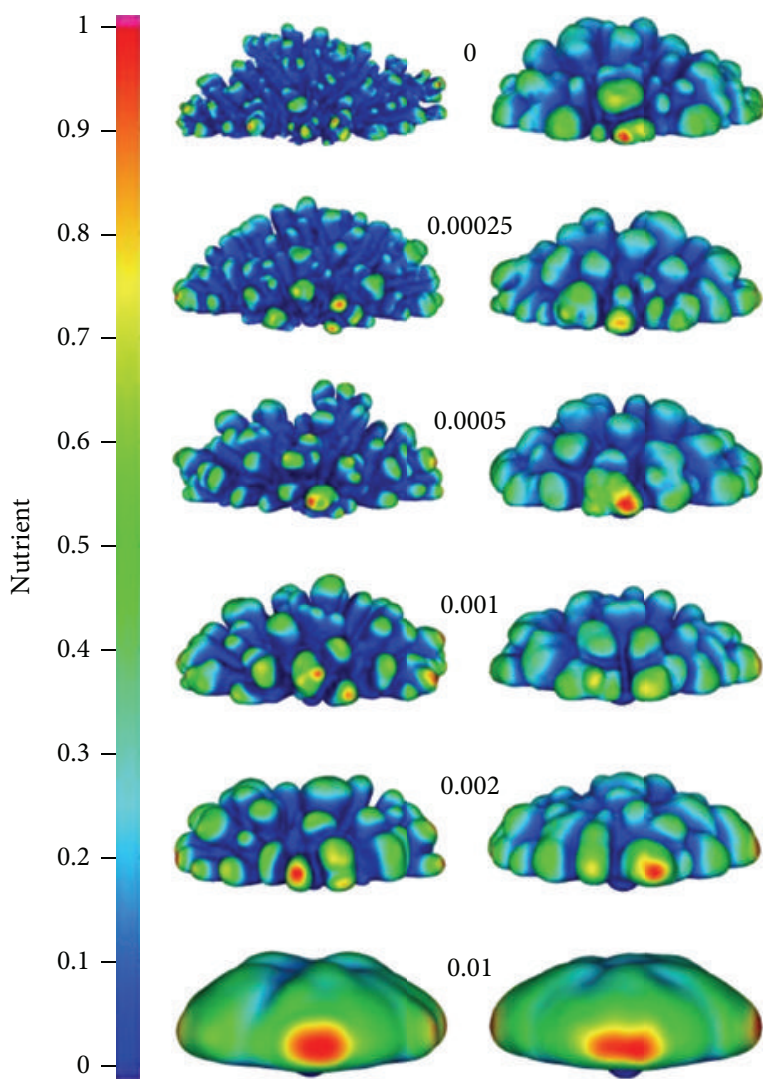

FIGURE 8: A range of simulated objects for $\alpha=0$ (4) with varying values for the surface diffusion constant $D_{\text {surf }}$ in (7) (the values are shown in the middle) and polygon spacing $d 1.9$ lattice units (left) and 3.7 lattice units (right). 70 growth steps. Simulated nutrient is exclusively distributed by diffusion.

is a constant supply of silicate from the environment and silicate is continuously being absorbed, silicate gradients will emerge in the direct neighbourhood of the sponge. 


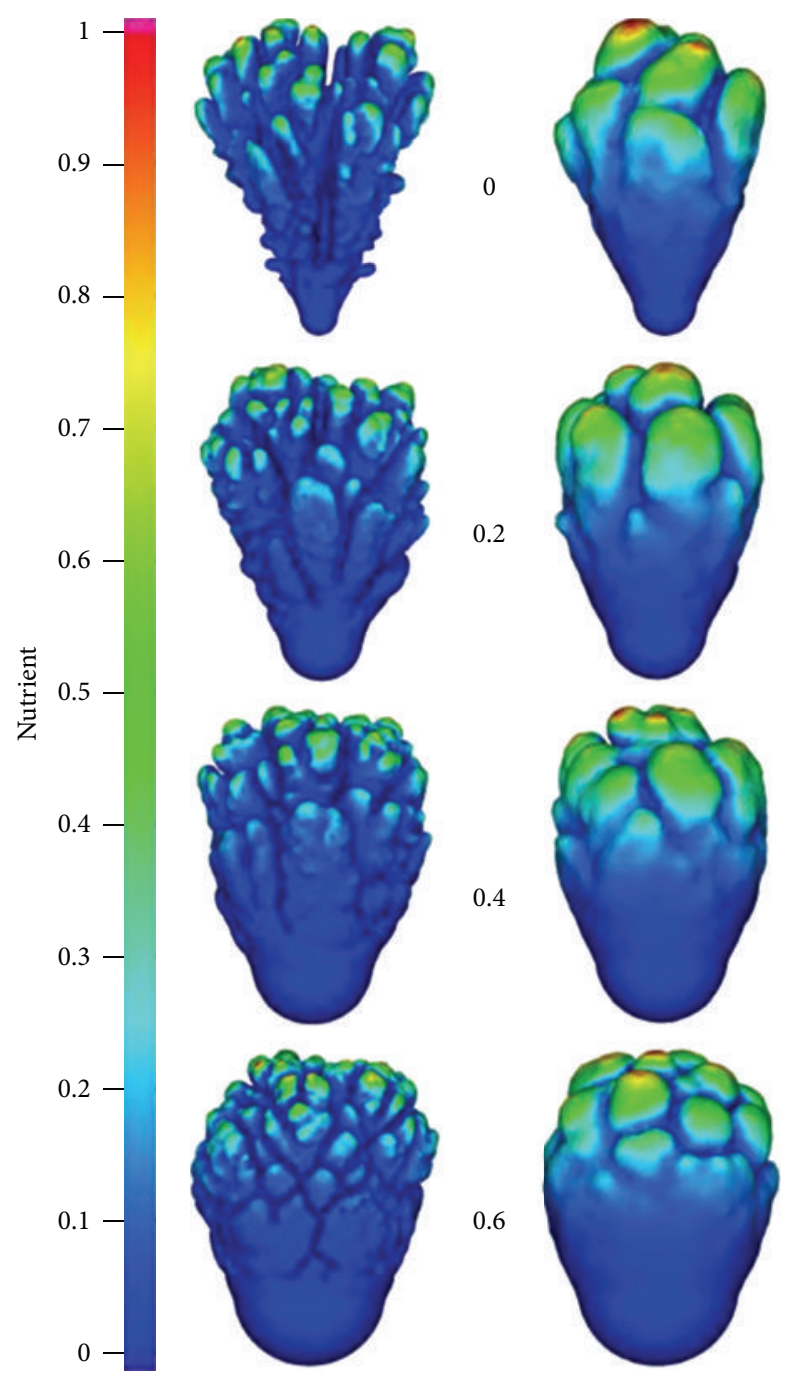

Figure 9: A range of simulated corals for $\alpha=0.4$ (4) with varying values in (5) for ambient (the values shown in the middle) and polygon spacing $d 1.9$ lattice units (left) and 3.7 lattice units (right). 85 growth steps. Simulated nutrient is exclusively distributed by diffusion.

High concentrations of silicate (or ferric ions) induce spicule formation and upregulate the silicatein, collagen, and myotrophin genes [96]. The upregulation of the genes activates the production of spicules in the sponge and leads to the deposition of the skeleton. The second major morphogenetic event is the construction of the aquiferous system together with formation of the exhalant pores. Only after the skeleton has been built, the aquiferous system is constructed. The expression of the gene Iroquois is induced by an increased water current and activates the formation of exhalant pores and the aquiferous system $[99,102]$. During the formation of this aquiferous system, some material has to be removed from the original skeleton, and skeletogenesis is stopped in the regions of the sponge where the aquiferous system is formed. Exhalant pores are formed at more or less regular distances from each other (see Figures 1(c) and $1(\mathrm{~d})$ ); this suggests a feedback mechanism preventing

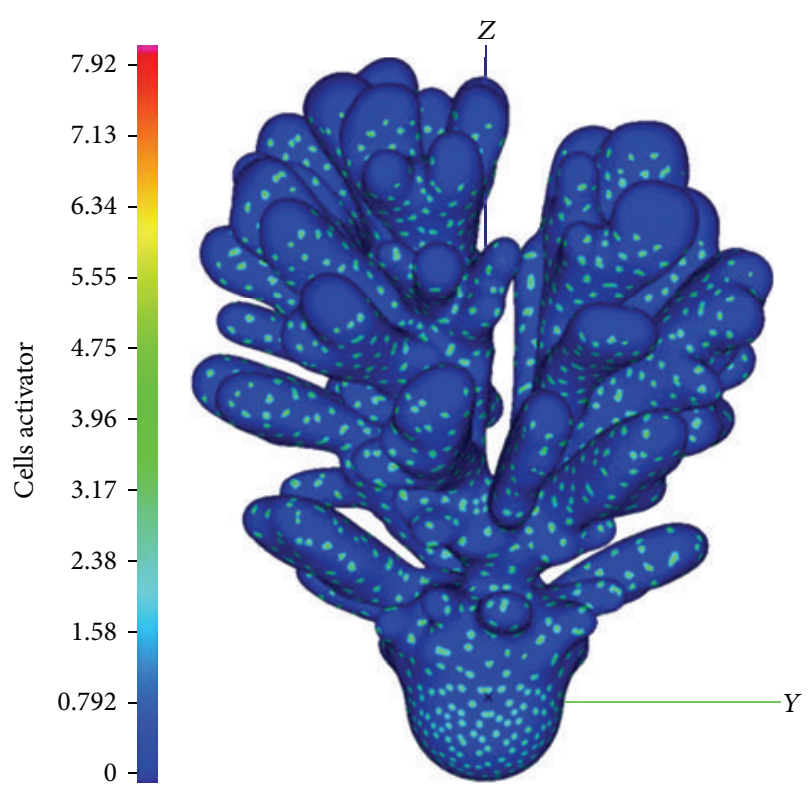

FIGURE 10: Simulated growth form and body plan of a branching sponge. The light spots indicate relatively high concentrations of Iroquois and mark the future positions of the exhalant pores. Simulated nutrient is exclusively distributed by diffusion.

Iroquois to be expressed everywhere on the surface which would lead to a disintegration of the sponge. The regulator suppressing Iroquois is not yet known. Furthermore, both the skeletogenesis and the formation of exhalant pores are processes occurring more or less at the surface of the sponge. It has been demonstrated in the sponge Suberites domuncula that the gene Frizzled works as a polarity factor in the sponge [98]. In Suberites domuncula Frizzled is expressed at the surface of the sponge. It is hypothesized here that Frizzled works as a positional information system, indicating the "up" direction (the direction towards the external environment in a branching sponge).

After determining the amount of silicate absorbed by the area around each vertex of the mesh object in the accretive growth model, a system of coupled differential equations is used to simulate the regulatory network controlling the formation of the exhalant pores. In the model Frizzled is only expressed at the surface of the sponge. We hypothesise that only in the presence of an constant) amount of Frizzled the other gene products can be activated. Therefore all simulated interactions take place only at the surface of the growth form. Three gene products are considered: silicatein (sil), Iroquois (irq), and an inhibitor of Iroquois (inh). In the model silicatein product (sil), Iroquois product (irq), and the inhibitor of Iroquois (inh) can freely diffuse over the simulated sponge surface, not hindered by cells, spicules, or other sponge structures. The amount of silicatein is set equal to the amount of normalised absorbed silicate at each growth step. Iroquois is produced when the concentration of silicatein drops below a certain threshold. The third gene product inhibits the production of Iroquois. To simulate the expression pattern of Iroquois we use a Gierer-Meinhardt model $[61,105]$ for 


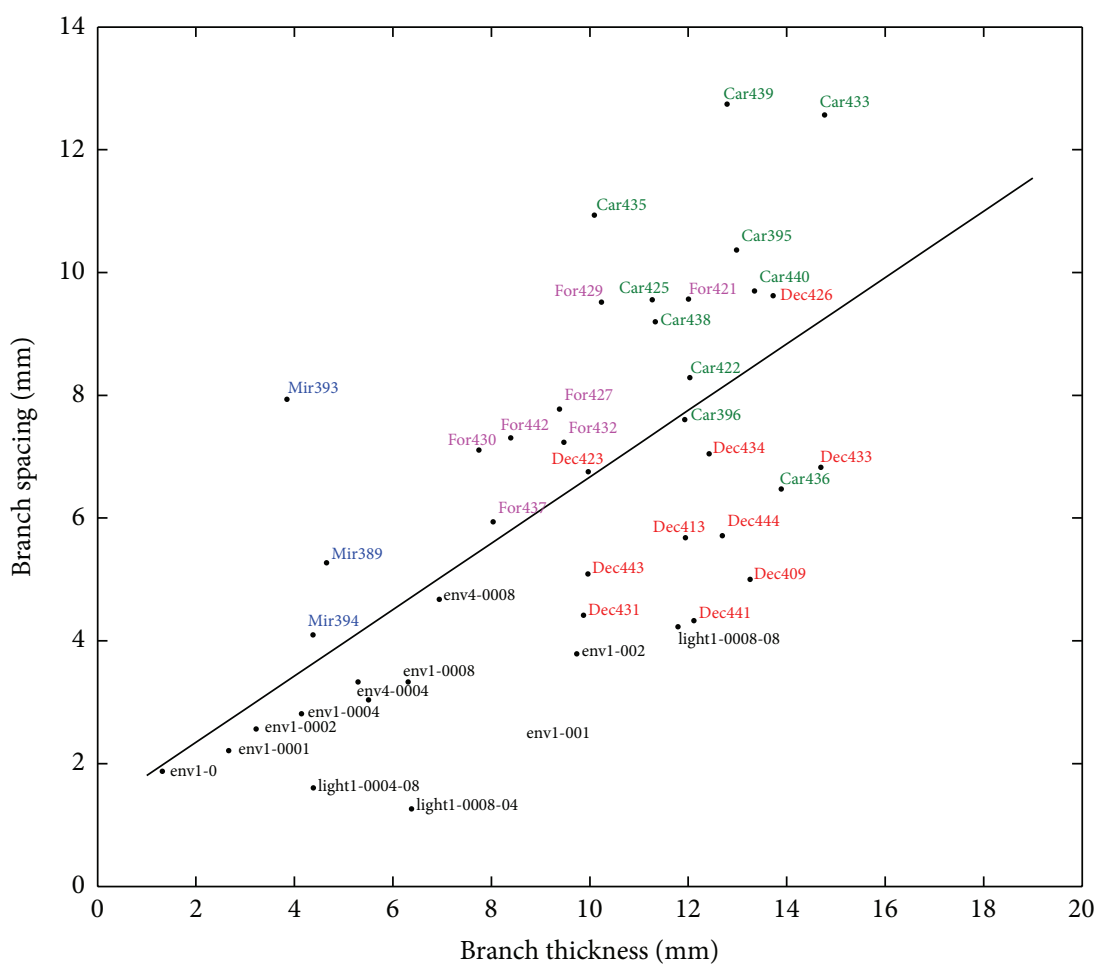

FIGURE 11: Plot of the correlation between branch thickness and branch spacing (see [8] for details). In colored labels of real corals the first three characters denote the name of the species, that is, Mir $\equiv$ M. mirabilis, For $\equiv$ M. formosa, Dec $\equiv M$. decactis, and Car $\equiv M$. carmabi. Followed by the ID number in our database. The corals M. mirabilis (Mir393 and Mir394) are, respectively, shown in Figures 1(a) and 1(b). Simulated growth forms are denoted using black labels, followed by the value of surface diffusion coefficient $D_{\text {surf }}$ (7). In simulations where the influence of light is taken into account (light1) the value of the surface diffusion coefficient is followed by the value of light intensity parameter $\alpha$ (4).

the production of Iroquois and the inhibition of Iroquois. Equation (3) describes the regulatory system

$$
\frac{\partial \rho(x, t)}{\partial t}=D \nabla^{2} \rho(x, t)-\lambda \rho(x, t)+R(\rho(x, t))
$$

with $\rho=\left(\rho_{\text {irq }}, \rho_{\text {inh }}\right)$ the concentrations of Iroquois and its inhibitor, respectively, $x$ is a two-dimensional spatial variable on the surface, $t$ is time, and $D$ and $\lambda$ are diagonal matrices with the respective diffusion and decay coefficients. The first term in the equation describes the diffusion of the gene products over the sponge surface. Decay of the products is modelled by the second term, while the third term governs the reaction between the gene products. In addition Iroquois is suppressed by silicatein which is, due to the absorption process, predominantly present at the top of the branches. The reaction-diffusion calculations are done after the silicate absorption. We use a method for surface diffusion on triangulated manifolds $[61,106]$ to update the concentrations of all the gene products at each iteration of the reaction-diffusion processes on the triangulised growth layer. After each growth step (8) is solved until steady state. Note that this approach implicitly assumes a separation of time scales: a slow accretive growth and a fast reaction-diffusion process on the surface of the sponge. An example of a model where we have combined the nutrient limited growth model and the simple model of gene regulation in (8) is shown in Figure 10.

\section{Discussion}

In Figures 8 and 9 we demonstrate that we can generate a large range of different morphologies with the radiate accretive growth model. The only species-specific information included in this example is the average size of a corallite or spicule (the parameter $d$ in the model). With the incorporation of simple local rules, controlling the size of individual simulated polygons, and local gradients it is possible to generate branching morphologies which approximate the morphologies of surface renderings of CT scans of $M$. mirabilis shown in Figures 1(a) and 1(b). In Figure 11 (see [8] for details) we make a quantitative comparison between threedimensional images of different Madracis species. In Figure 11 the average branch thickness and the average branch spacing are quantified in four different Madracis species (the coloured labels) and in the simulated objects (the black labels). This figure shows that we can approximate the morphology of certain Madracis species (e.g., M. mirabilis) very well, while in some other Madracis species (e.g., M. carmabi) we are still missing something in our model to get a good morphology (a morphology which is visually virtually indistinguishable from an actual object) approximation. Hydrodynamics, the structure of individual corallites, and interpolyp communication are not modelled in this paper. In a recent paper [8] we demonstrate how hydrodynamics can be incorporated in this model. The examples in Figures 8 and 9 show that some 
basic principles of the coral colony morphogenesis can be captured in a computational model. The demonstrated range of simulated shapes can be significantly extended in at least another dimension by adding physiological or genetic factors that will regulate the growth of a colony from within.

In Figure 10 we show an (very simplistic) example of how the radiate accretive growth model can be coupled with a spatiotemporal model of gene regulation. In Figure 10 an example of the simulated sponge is shown: the light blue spots with a relatively high upregulation of Iroquois indicate the future positions of the exhalant pores. In Figure 10, there is a clear separation in time and space of the growing zones (dark blue regions at the tips without spots, where silicatein is expressed and Iroquois is suppressed) and the zones where exhalant pores are formed. The tips in the upper branches which are most recently formed do not contain spots yet. The spots are later on formed in the growth process, resulting in spots covering the regions below the tips of the branches. Growth occurs in the dark blue regions without spots where relatively high concentrations of environmental silicate activate silicatein. The gene product of silicatein is produced near the surface (with high concentrations of Frizzled product) and diffuses through the sponge. As soon as the growth process stops when the silicate concentration is nearly depleted, the silicatein gene is suppressed and the Iroquois gene is activated.

In a section (Figure 6(a))the accretive model displays a radiate accretive architecture comparable to a longitudinal section through a branch of the sponge as shown in Figure 2(b). In Figure 10, the growing zones are visible as dark blue regions without light blue spots. An exception can be seen at the lower left branch, which is shielded by the other branches; growth stopped due to a local depletion of silicate and suppression of Iroquois is stopped, leading to the formation of exhalant pores on the tip. This phenomenon can also be observed in actual sponges.

\section{References}

[1] D. J. Barnes, "Growth in colonial scleractinians," Bulletin of Marine Science, vol. 23, pp. 280-298, 1973.

[2] R. R. Graus and I. G. Macintyre, "Variation in growth forms of the reef coral Montastrea annularis (Ellis and Solander): a quantitative evaluation of growth response to light distribution using computer simulation," Smithsonian Contributions to the Marine Sciences, vol. 12, pp. 441-464, 1982.

[3] C. W. Stearn and R. Riding, "Forms of the hydrozoan Millepora on a recent coral reef," Lethaia, vol. 6, pp. 187-200, 1973.

[4] W. H. de Weerdt, "Transplantation experiments with Caribbean Millepora species (Hydrozoa, Coelenterata), including some ecological observations on growth forms," Bijdr Dierk, vol. 51, no. 1, pp. 1-19, 1981.

[5] M. P. Lesser, V. M. Weis, M. R. Patterson, and P. L. Jokiel, "Effects of morphology and water motion on carbon delivery and productivity in the reef coral, Pocillopora damicornis (Linnaeus): diffusion barriers, inorganic carbon limitation, and biochemical plasticity," Journal of Experimental Marine Biology and Ecology, vol. 178, no. 2, pp. 153-179, 1994.

[6] N. Chindapol, J. A. Kaandorp, C. Cronemberger, T. Mass, and A. Genin, "Modelling growth and form of the scleractinian coral
Pocillopora verrucosa and the influence of hydrodynamics," Plos Computational Biology, vol. 9, no. 1, Article ID 100284, 2013.

[7] K. P. Sebens, J. Witting, and B. Helmuth, "Effects of water flow and branch spacing on particle capture by the reef coral Madracis mirabills (Duchassaing and Michelotti)," Journal of Experimental Marine Biology and Ecology, vol. 211, no. 1, pp. 128, 1997.

[8] M. V. Filatov, J. A. Kaandorp, M. Postma et al., "A comparison between coral colonies from the Madracis genus and simulated forms," Proceedings of the Royal Society B, vol. 277, pp. 35553561,2010

[9] B. Helmuth and K. Sebens, "The influence of colony morphology and orientation to flow on particle capture by the scleractinian coral Agaricia agaricites (Linnaeus)," Journal of Experimental Marine Biology and Ecology, vol. 165, no. 2, pp. 251-278, 1993.

[10] D. Jebram, "Influences of the food on the colony forms of Electra pilosa (Bryozoa, Cheilostomata)," Zoologische Jahrbücher. Abteilung für Systematik, vol. 108, pp. 1-14, 1980.

[11] D. W. J. Bosence, "Ecological studies on two unattached coralline algae from western Ireland," Palaeontology, vol. 19, no. 2, pp. 365-395, 1976.

[12] J. A. Kaandorp, "Modelling growth forms of the sponge Haliclona oculata (Porifera, Demospongiae) using fractal techniques," Marine Biology, vol. 110, no. 2, pp. 203-215, 1991.

[13] J. A. Kaandorp and M. J. de Kluijver, "Verification of fractal growth models of the sponge Haliclona oculata (Porifera) with transplantation experiments," Marine Biology, vol. 113, no. 1, pp. 133-143, 1992.

[14] P. A. Todd, "Morphological plasticity in scleractinian corals," Biological Reviews, vol. 83, no. 3, pp. 315-337, 2008.

[15] K. J. Kruszyński, J. A. Kaandorp, and R. van Liere, "A computational method for quantifying morphological variation in scleractinian corals," Coral Reefs, vol. 26, no. 4, pp. 831-840, 2007.

[16] F. L. Bookstein, Morphometric Tools for Landmark Data: Geometry and Biology, Cambridge University Press, New York, NY, USA, 1991.

[17] D. Stoyan and F. L. Bookstein, Morphometric Tools for Landmark Data. Geometry and Biology, Cambridge University Press, Cambridge, UK, 1993.

[18] J. L. Harper, B. R. Rosen, and J. White, The Growth and Form of Modular Organisms, The Royal Society London, London, UK, 1986.

[19] J. B. C. Jackson, L. W. Bass, and R. E. Cock, Population Biology and Evolution of Clonal Organisms, Yale University Press, London, UK, 1985.

[20] J. A. Sánchez and H. R. Lasker, "Patterns of morphological integration in marine modular organisms: supra-module organization in branching octocoral colonies," Proceedings of the Royal Society B, vol. 270, no. 1528, pp. 2039-2044, 2003.

[21] J. A. Sánchez, H. R. Lasker, E. G. Nepomuceno, J. D. Sánchez, and M. J. Woldenberg, "Branching and self-organization in marine modular colonial organisms: a model," The American Naturalist, vol. 163, no. 3, pp. E24-E39, 2004.

[22] T. Vuorisalo and J. Tuomi, "Unitary and modular organisms: criteria for ecological division," Oikos, vol. 47, no. 3, pp. 382385, 1986.

[23] K. Kim and H. R. Lasker, "Allometry of resource capture in colonial cnidarians and constraints on modular growth," Functional Ecology, vol. 12, no. 4, pp. 646-654, 1998.

[24] J. E. N. Veron and M. Pichon, Scleractinia of Eastern Australia Part Families Thamnasteriidae, Astrocoeniidae, Pocilloporidae, 
Australian Government Publishing Service, Canberra, Australia, 1976.

[25] J. A. Kaandorp, E. A. Koopman, P. M. A. Sloot, R. P. M. Bak, M. J. A. Vermeij, and L. E. H. Lampmann, "Simulation and analysis of flow patterns around the scleractinian coral Madracis mirabilis (Duchassaing and Michelotti)," Philosophical Transactions of the Royal Society B, vol. 358, no. 1437, pp. 1551-1557, 2003.

[26] J. A. Chamberlain and R. R. Graus, "Water flow and hydromechanical adaptations of branched reef corals," Bulletin of Marine Science, vol. 25, pp. 112-125, 1977.

[27] K. R. N. Anthony, "Coral suspension feeding on fine particulate matter," Journal of Experimental Marine Biology and Ecology, vol. 232, pp. 85-106, 1999.

[28] M. J. Atkinson and R. W. Bilger, "Effects of water velocity on phosphate uptake in coral reef-flat communities," Limnology and Oceanography, vol. 37, no. 2, pp. 273-279, 1992.

[29] F. I. M. Thomas and M. J. Atkinson, "Ammonium uptake by coral reefs: effects of water velocity and surface roughness on mass transfer," Limnology and Oceanography, vol. 42, no. 1, pp. 81-88, 1997.

[30] B. D. Badgley, F. Lipschultz, and K. P. Sebens, "Nitrate uptake by the reef coral Diploria strigosa: effects of concentration, water flow, and irradiance," Marine Biology, vol. 149, no. 2, pp. 327338, 2006.

[31] R. Riedl, "Water movement-animal," in Marine Ecology, O. Kinne, Ed., vol. 1, pp. 1123-1156, John Wiley \& Sons, New York, NY, USA, 1971.

[32] K. P. Sebens and A. S. Johnson, "Effects of water movement on prey capture and distribution of reef corals," Hydrobiologia, vol. 226, no. 2, pp. 91-101, 1991.

[33] W. C. Dennison and D. J. Barnes, "Effect of water motion on coral photosynthesis and calcification," Journal of Experimental Marine Biology and Ecology, vol. 115, pp. 67-77, 1988.

[34] M. R. Patterson, K. P. Sebens, and R. R. Olson, "In situ measurements of flow effects on primary production and dark respiration in reef corals," Limnology and Oceanography, vol. 36, no. 5, pp. 936-948, 1991.

[35] Y. I. Sorokin, Coral Reef Ecology, Springer, Heidelberg, Germany, 1993.

[36] F. Marubini and B. Thake, "Bicarbonate addition promotes coral growth," Limnology and Oceanography, vol. 44, no. 3 I, pp. 716720, 1999.

[37] F. Marubini, C. Ferrier-Pages, and J. P. Cuif, "Suppression of skeletal growth in scleractinian corals by decreasing ambient carbonate-ion concentration: a cross-family comparison," Proceedings of the Royal Society B, vol. 270, no. 1511, pp. 179-184, 2003.

[38] M. A. Reidenbach, J. R. Koseff, S. G. Monismith, J. V. Steinbuck, and A. Genin, "The effects of waves and morphology on mass transfer within branched reef corals," Limnology and Oceanography, vol. 51, no. 2, pp. 1134-1141, 2006.

[39] S. Chang, C. Elkins, M. Alley, J. Eaton, and S. Monismith, "Flow inside a coral colony measured using magnetic resonance velocimetry," Limnology and Oceanography, vol. 54, no. 5, pp. 1819-1827, 2009.

[40] S. G. Monismith, "Hydrodynamics of coral reefs," Annual Review of Fluid Mechanics, vol. 39, pp. 37-55, 2007.

[41] P. L. Jokiel, "Ocean acidification and control of reef coral calcification by boundary layer limitation of proton flux," Bulletin of Marine Science, vol. 87, no. 3, pp. 639-657, 2011.

[42] P. L. Jokiel, "The reef coral two compartment proton flux model: a new approach relating tissue-level physiological processes to gross corallum morphology," Journal of Experimental Marine Biology and Ecology, vol. 409, pp. 1-12, 2011.

[43] T. A. McConnaughey, J. Burdett, J. F. Whelan, and C. K. Paull, "Carbon isotopes in biological carbonates: respiration and photosynthesis," Geochimica et Cosmochimica Acta, vol. 61, no. 3, pp. 611-622, 1997.

[44] J. M. Heikoop, J. J. Dunn, M. J. Risk, H. P. Schwarcz, T. A. McConnaughey, and I. M. Sandeman, "Separation of kinetic and metabolic isotope effects in carbon-13 records preserved in reef coral skeletons," Geochimica et Cosmochimica Acta, vol. 64, no. 6, pp. 975-987, 2000.

[45] C. Maier, J. Pätzold, and R. P. M. Bak, "The skeletal isotopic composition as an indicator of ecological and physiological plasticity in the coral genus Madracis," Coral Reefs, vol. 22, no. 4, pp. 370-380, 2003.

[46] T. Mass and A. Genin, "Environmental versus intrinsic determination of colony symmetry in the coral Pocillopora verrucosa," Marine Ecology Progress Series, vol. 369, pp. 131-137, 2008.

[47] T. Mass, A. Genin, U. Shavit, M. Grinstein, and D. Tchernov, "Flow enhances photosynthesis in marine benthic autotrophs by increasing the efflux of oxygen from the organism to the water," Proceedings of the National Academy of Sciences of the United States of America, vol. 107, no. 6, pp. 2527-2531, 2010.

[48] T. Mass, I. Brickner, E. Hendy, and A. Genin, "Enduring physiological and reproductive benefits of enhanced flow for a stony coral," Limnology and Oceanography, vol. 56, pp. 2176-2188, 2011.

[49] D. R. Webster and M. J. Weissburg, "The hydrodynamics of chemical cues among aquatic organisms," Annual Review of Fluid Mechanics, vol. 41, pp. 73-90, 2009.

[50] J. F. Bruno and P. J. Edmunds, "Metabolic consequences of phenotypic plasticity in the coral Madracis mirabilis (Duchassaing and Michelotti): the effect of morphology and water flow on aggregate respiration," Journal of Experimental Marine Biology and Ecology, vol. 229, no. 2, pp. 187-195, 1998.

[51] S. Muko, K. Kawasaki, K. Sakai, F. Takasu, and N. Shigesada, "Morphological plasticity in the coral Porites sillimaniani and its adaptive significance," Bulletin of Marine Science, vol. 66, no. 1, pp. 225-239, 2000.

[52] J. A. Kaandorp, "A formal description of radiate accretive growth," Journal of Theoretical Biology, vol. 166, no. 2, pp. 149$161,1994$.

[53] J. A. Kaandorp, Fractal Modelling: Growth and Form in Biology, Springer, Berlin, Germany, 1994.

[54] J. A. Kaandorp, "Morphological analysis of growth forms of branching marine sessile organisms along environmental gradients," Marine Biology, vol. 134, no. 2, pp. 295-306, 1999.

[55] P. Brien, C. Lévi, M. Sara, O. Tuzet, and J. Vacelet, Traité de Zoologie: Anatomie, Systématique, Biologie, Tome III Spongiares, chapter 1, Paris, France, 1973.

[56] J. A. Kaandorp and J. E. Kuebler, The Algorithmic Beauty of Seaweeds, Sponges and Corals, Springer, Heidelberg, Germany, 2001.

[57] W. H. de Weerdt, "A systematic revision of the north-eastern Atlantic shallow-water Haplosclerida (Porifera, Demospongiae), part II: Chalinidae," Beaufortia, vol. 36, pp. 81-165, 1986.

[58] S. Vogel, "Current-induced flow through the sponge, Halichondria," Biological Bulletin, vol. 147, no. 2, pp. 443-456, 1974.

[59] J. P. Grotzinger and D. H. Rothman, "An abiotic model for stromatolite morphogenesis," Nature, vol. 383, no. 6599, pp. 423-425, 1996.

[60] M. R. Walter, Stromatolites, Elsevier, Amsterdam, The Netherlands, 1976. 
[61] J. A. Kaandorp, J. G. Blom, J. Verhoef, M. Filatov, M. Postma, and W. E. G. Müller, "Modelling genetic regulation of growth and form in a branching sponge," Proceedings of the Royal Society B, vol. 275, pp. 2569-2577, 2008.

[62] J. A. Kaandorp, C. P. Lowe, D. Frenkel, and P. M. A. Sloot, "Effect of nutrient diffusion and flow on coral morphology," Physical Review Letters, vol. 77, no. 11, pp. 2328-2331, 1996.

[63] J. A. Kaandorp, P. M. A. Sloot, R. M. H. Merks, R. P. M. Bak, M. J. A. Vermeij, and C. Maier, "Morphogenesis of the branching reef coral Madracis mirabilis," Proceedings of the Royal Society $B$, vol. 272, pp. 127-133, 2005.

[64] R. M. H. Merks, A. G. Hoekstra, J. A. Kaandorp, and P. M. A. Sloot, "Polyp oriented modelling of coral growth," Journal of Theoretical Biology, vol. 228, no. 4, pp. 559-576, 2004.

[65] W. E. Lorensen and H. E. Cline, "Marching cubes: a high resolution 3D surface construction algorithm," ACM Computer Graphics, vol. 21, no. 4, pp. 163-169, 1987.

[66] J. A. Kaandorp and P. M. A. Sloot, "Morphological models of radiate accretive growth and the influence of hydrodynamics," Journal of Theoretical Biology, vol. 209, no. 3, pp. 257-274, 2001.

[67] J. A. Kaandorp, M. Filatov, and N. Chindapol, "Simulating and quantifying the environmental influence on coral growth and form," in Coral Reefs: An Ecosystem in Transition, Z. Dubinsky and N. Stambler, Eds., part 3, pp. 177-185, 2011.

[68] W. M. Darke and D. J. Barnes, "Growth trajectories of corallites and ages of polyps in massive colonies of reef-building corals of the genus Porites," Marine Biology, vol. 117, no. 2, pp. 321-326, 1993.

[69] M. Le Tissier, B. Clayton, B. E. Brown, and P. Spencer Davies, "Skeletal correlates of coral density banding and an evaluation of radiography as used in scelerochronology," Marine Ecology Progress Series, vol. 110, pp. 29-44, 1994.

[70] W. Schroeder, K. Martin, and B. Lorensen, The Visualization Toolkit: An Object-Oriented Approach To 3D Graphics, Prentice Hall, New Jersey, NJ, USA, 2nd edition, 1997.

[71] O. V. Kaluzhnaya, S. I. Belikov, H. C. Schrider et al., "Dynamics of skeletal formation in the Lake Baikal sponge Lubomirskia baicalensis. Part I. Biological and biochemical studies," Naturwissenschaften, vol. 92, pp. 128-133, 2005.

[72] O. V. Kaluzhnaya, S. I. Belikov, H. C. Schr öder et al., "Dynamics of skeletal formation in the Lake Baikal sponge Lubomirskia baicalensis. Part II. Molecular biological studies," Naturwissenschaften, vol. 92, pp. 134-138, 2005.

[73] F. Wiedenmayer, Shallow-Water Sponges of the Western Bahamas, Birkhäuser, Basel, Switzerland, 1977.

[74] C. P. Lowe and D. Frenkel, "The super long-time decay of velocity fluctuations in a two-dimensional fluid," Physica A, vol. 220, no. 3-4, pp. 251-260, 1995.

[75] R. M. H. Merks, A. G. Hoekstra, and P. M. A. Sloot, "The moment propagation method for advection-diffusion in the Lattice Boltzmann method: validation and Péclet number limits," Journal of Computational Physics, vol. 183, no. 2, pp. 563576, 2002.

[76] A. J. C. Ladd, "Numerical simulations of particulate suspensions via a discretized Boltzmann equation. Part 1 . Theoretical foundation," Journal of Fluid Mechanics, vol. 271, pp. 285-309, 1994.

[77] A. J. C. Ladd, "Numerical simulations of particulate suspensions via a discretized Boltzmann equation. Part 2. Numerical results," Journal of Fluid Mechanics, vol. 271, pp. 311-339, 1994.

[78] B. Chopard and M. Droz, Cellular Automata Modelling of Physical Systems, Cambridge Univerity Press, 1998.

[79] S. Succi, The Lattice Boltzmann Equation: for Fluid Dynamics and Beyond, Oxford University Press, 2001.
[80] A. Koponen, D. Kandhai, E. Hellén et al., "Permeability of threedimensional random fiber webs," Physical Review Letters, vol. 80, no. 4, pp. 716-719, 1998.

[81] D. Kandhai, D. Hlushkou, A. G. Hoekstra, P. M. A. Sloot, H. Van As, and U. Tallarek, "Influence of stagnant zones on transient and asymptotic dispersion in macroscopically homogeneous porous media," Physical Review Letters, vol. 88, no. 23, Article ID 234501, 4 pages, 2002.

[82] COMSOL Multiphysics, “3.5a. COMSOL AB,” Palo Alto, Calif, USA, 2009, http://www.comsol.com/.

[83] R. Merks, A. Hoekstra, J. Kaandorp, and P. Sloot, "Models of coral growth: spontaneous branching, compactification and the Laplacian growth assumption," Journal of Theoretical Biology, vol. 224, no. 2, pp. 153-166, 2003.

[84] J. Verhoef, Morph space exploration of the accretive growth model [M.S. thesis], University of Amsterdam, 2006.

[85] J. Huang, R. Yagel, V. Filippov, and Y. Kurzion, "An accurate method for voxelizing polygon meshes," in Proceedings of the ACE/IEEE Symposium on Volume Visualization, pp. 119-126, 1998.

[86] A. Kaufman, "Efficient algorithms for scan-converting 3D polygons," Computers and Graphics, vol. 12, no. 2, pp. 213-219, 1988.

[87] A. Kaufman, "Efficientalgorithms for 3D scan-conversion of parametric curves, surfaces and volumes," Computer Graphics, vol. 21, no. 4, pp. 269-277, 1987.

[88] B. E. Chalker and D. L. Taylor, "Light-enhanced calcification, and the role of oxidative phosphorylation in calcification of the coral Acropora cervicornis," Proceedings of the Royal Society of London B, vol. 190, no. 1100, pp. 323-331, 1975.

[89] B. Rinkevich and Y. Loya, "Does light enhance calcification in hermatypic corals?" Marine Biology, vol. 80, no. 1, pp. 1-6, 1984.

[90] J. P. Gairuso, D. Allemand, and M. Frankignoulle, "Photosynthesis and calcification at cellular, organismal and community levels in coral reefs: a review on interactions and control by carbonate chemistry," American Zoologist, vol. 39, no. 1, pp. 160183, 1999.

[91] D. Allemand, C. Ferrier-Pagès, C. Furla et al., "Biomineralisation in reef-building corals: from molecular mechanisms to environmental control," Comptes Rendus Palevol, vol. 3, no. 6-7, pp. 453-467, 2004.

[92] F. A. Al-Horani, S. M. Al-Moghrabi, and D. de Beer, "The mechanism of calcification and its relation to photosynthesis and respiration in the scleractinian coral Galaxea fascicularis," Marine Biology, vol. 142, no. 3, pp. 419-426, 2003.

[93] F. A. Al-Horani, S. M. Al-Moghrabi, and D. de Beer, "Microsensor study of photosynthesis and calcification in the scleractinian coral, Galaxea fascicularis: active internal carbon cycle," Journal of Experimental Marine Biology and Ecology, vol. 288, no. 1, pp. $1-15,2003$.

[94] F. A. Al-Horani, E. Tambutte, and D. Allemand, "Dark calcification and the daily rhythm of calcification in the scleractinian coral, Galaxea fascicularis," Coral Reefs, vol. 26, no. 3, pp. 531538, 2007.

[95] A. Moya, S. Tambutté, E. Tambutté, D. Zoccola, N. Caminiti, and D. Allemand, "Study of calcification during a daily cycle of the coral Stylophora pistillata: implications for 'light-enhanced calcification"' The Journal of Experimental Biology, vol. 209, no. 17, pp. 3413-3419, 2006.

[96] G. Le Pennec, S. Perovic, M. S. A. Ammar et al., "Cultivation of primmorphs from the marine sponge Suberites domuncula: morphogenetic potential of silicon and iron," Journal of Biotechnology, vol. 100, no. 2, pp. 93-108, 2003. 
[97] B. Rinkevich and Y. Loya, "Oriented translocation of energy in grafted reef corals," Coral Reefs, vol. 1, no. 4, pp. 243-247, 1983.

[98] T. Adell, I. Nefkens, and W. E. G. Müller, "Polarity factor "Frizzled" in the demosponge Suberites domuncula: identification, expression and localization of the receptor in the epithelium/pinacoderm," FEBS Letters, vol. 554, pp. 363-368, 2003.

[99] S. Perovic, H. C. Schrider, S. Sudek et al., "Expression of one sponge Iroquois homeobox gene in primmorphs from Suberites domuncula during canal formation," Evolution \& Development, vol. 5, pp. 240-250, 2003.

[100] W. E. G. Müller, A. Krasko, G. Pennec et al., "Molecular mechanism of spicule formation in the demosponge Suberites domuncula: silicatein-collagen- myotrophin," Progress in Molecular and Subcellular Biology, vol. 33, pp. 195-231, 2003.

[101] W. E. G. Müller, M. Wiens, T. Adell, V. Gamulin, H. C. Schröder, and I. M. Müller, "Bauplan of urmetazoa: basis for genetic complexity of metazoa," International Review of Cytology, vol. 235, pp. 53-92, 2004.

[102] W. E. G. Müller, M. Binder, J. von Lintig et al., "Interaction of the retinoic acid signaling pathway with spicule formation in the marine sponge Suberites domuncula through activation of bone morphogenetic protein'”' Biochimica et Biophysica Acta, vol. 1810, pp. 1178-1194, 2011.

[103] H. C. Schröder, F. Natalio, I. Shukoor et al., "Apposition of silica lamellae during growth of spicules in the demosponge Suberites domuncula: biological/biochemical studies and chemical/biomimetical confirmation," Journal of Structural Biology, vol. 159, no. 3, pp. 325-334, 2007.

[104] M. Wiens, S. I. Belikov, O. V. Kaluzhnaya et al., "Regional and modular expression of morphogenetic factors in the demosponge Lubomirskia baicalensis," Micron, vol. 39, no. 4, pp. 447460, 2008.

[105] A. Gierer and H. Meinhardt, "A theory of biological pattern formation," Kybernetik, vol. 12, no. 1, pp. 30-39, 1972.

[106] C. Zemlin, Rhytms and wave propogation in the heart [Ph.D. thesis], Humboldt-Universität zu Berlin, 2002. 


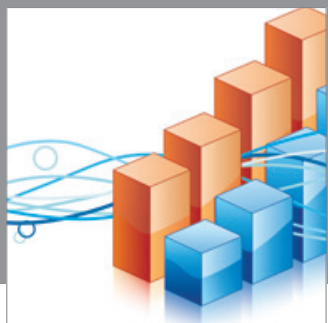

Advances in

Operations Research

mansans

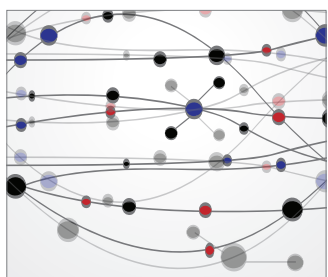

The Scientific World Journal
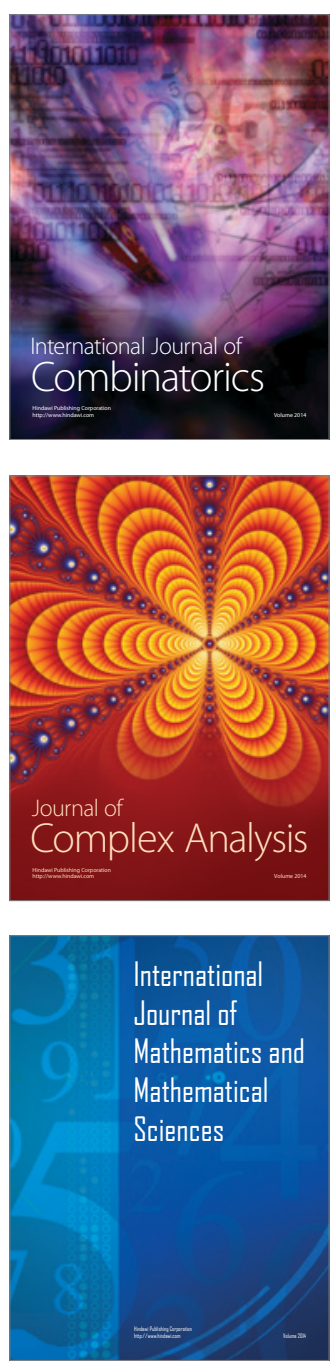
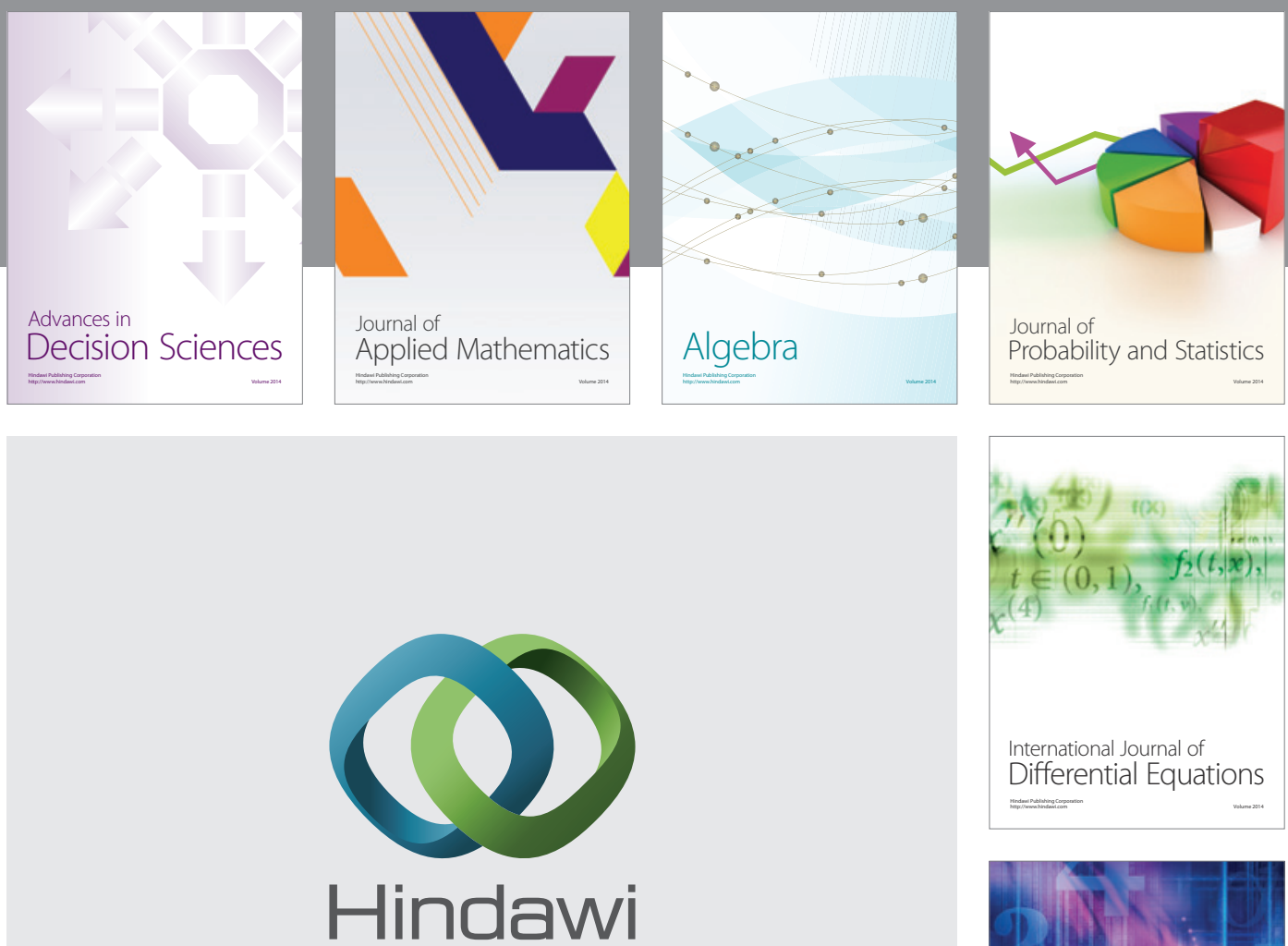

Submit your manuscripts at http://www.hindawi.com
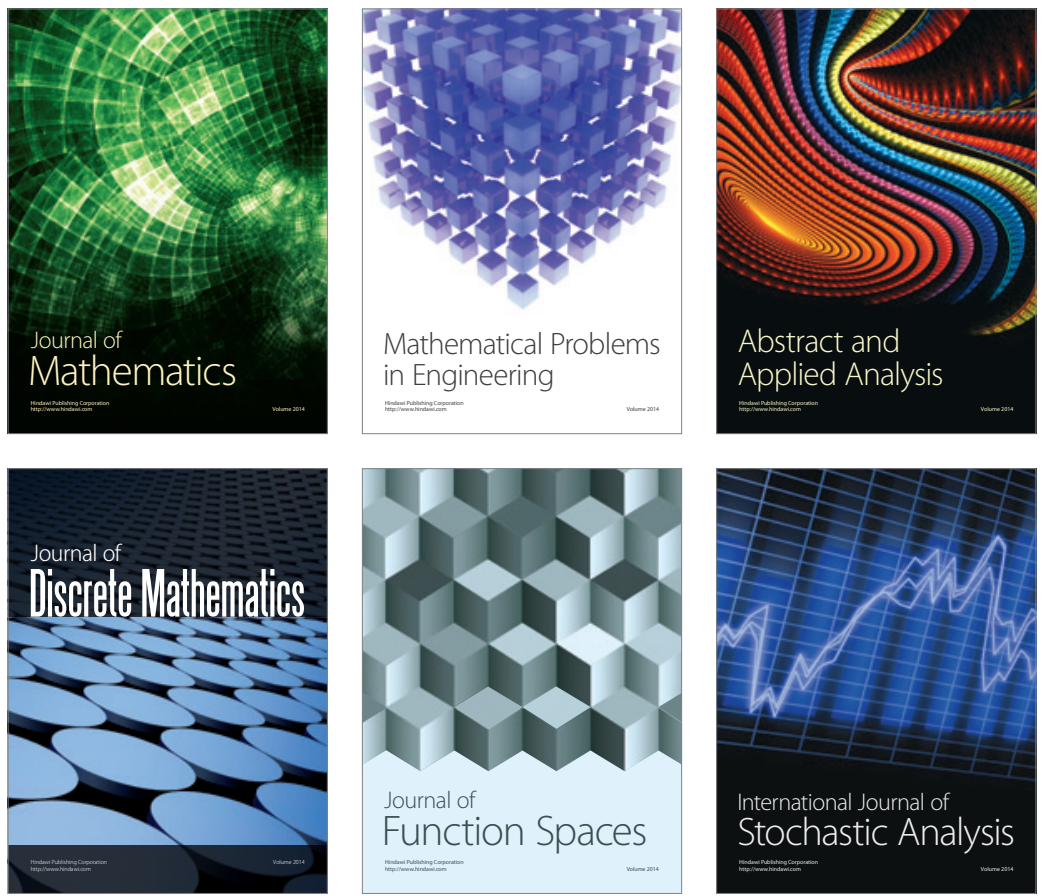

Journal of

Function Spaces

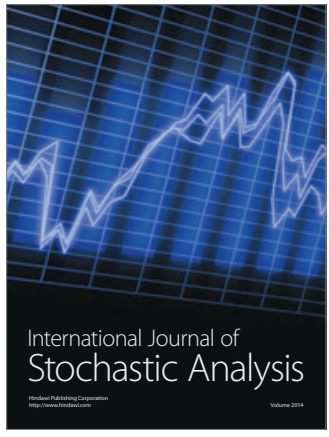

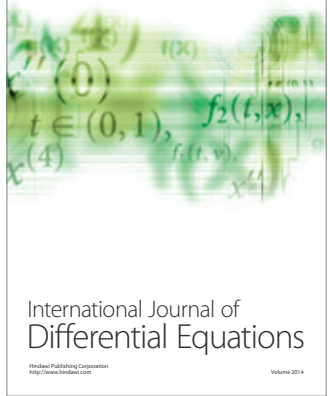
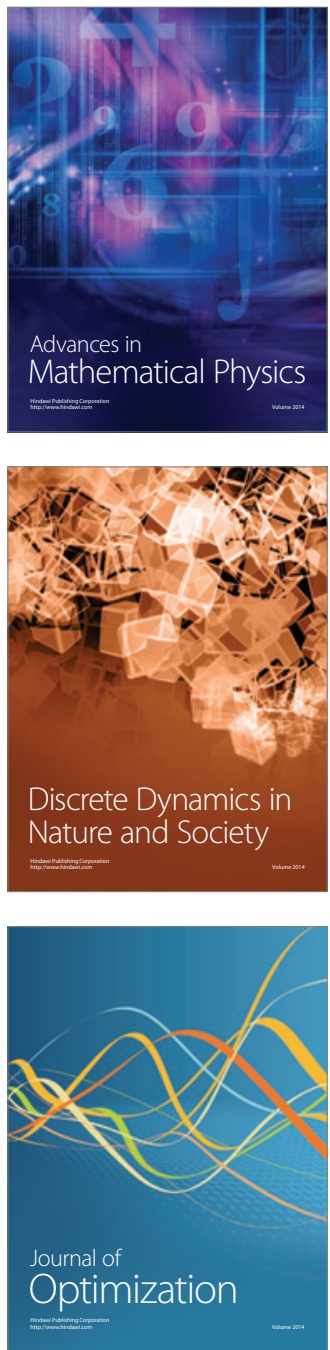